\title{
The Effect of Extracts and Essential Oil from Invasive Solidago spp. and Fallopia japonica on Crop-Borne Fungi and Wheat Germination
}

\author{
Sabina Anžlovar'®, Damjan \\ Janeš² $\odot$ and Jasna Dolenc \\ Koce $^{1 *}$ (e)
}

'Biotechnical Faculty, University of Ljubljana, Jamnikarjeva 101, 1000 Ljubljana, Slovenia

2Faculty of Pharmacy, University of Ljubljana, Aškerčeva 7, 1000 Ljubljana, Slovenia

Received: 16 January 2020 Accepted: 4 September 2020

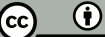

${ }^{*}$ Corresponding author:

Phone: +38613203325

Fax: +38612573390

E-mail: jasna.dolenc.koce@bf.uni-lj.si

\section{SUMMARY}

Research background. Many plant extracts and essential oils show antibacterial and antifungal activities, with potential to replace the use of synthetic fungicides. We used invasive alien plants goldenrod (Solidago spp.) and Japanese knotweed (Fallopia japonica) as source materials to determine their antifungal activities against seed-associated fungi from wheat grain (Alternaria alternata, Alternaria infectoria, Aspergillus flavus, Epicoccum nigrum and Fusarium poae).

Experimental approach. Aqueous and organic extracts (ethanol, methanol and acetone) were prepared from leaves and flowers of S. canadensis, S. gigantea and S. virgaurea, and leaves and rhizomes of $F$. japonica. Additionally, essential oils were distilled from Solidago flowers and leaves. The extracts and essential oils were tested as inhibitors of fungal growth in vitro. Solidago essential oils were tested also as antifungal agents for protection of wheat grain by determining its fungal infection and germination rate.

Results and conclusions. The extracts showed a wide spectrum of low to moderate antifungal activities, with those of Solidago spp. generally more effective than those of $F$. japonica, and organic extracts more effective than aqueous extracts. The essential oils from leaves and flowers had similar antifungal activity and whole shoots can be collected for their production. This study presents the systematic study of the composition of essential oils from flowers and leaves of three widely distributed Solidago spp. in Slovenia, with the major constituents of terpenes and terpenoids a-pinene, germacrene $D$ and bornyl acetate.

Novelty and scientific contribution. The study presents the first use of Solidago spp. and Fallopia japonica extracts and essential oils against fungal strains isolated from wheat grain.

Key words: antifungal activity, Fallopia japonica, essential oil, flower and leaf extracts, Solidago, Triticum aestivum

\section{INTRODUCTION}

Wheat (Triticum aestivum L.) is one of the most important cereal crops, and it is cultivated worldwide. During germination and growth in the field and during storage of the harvested grain, it is under constant attack by damaging microbes, such as seed-borne and soil-borne fungi (1). Fungal infections can have negative effects on wheat grain and result in economic losses. In a previous study, we isolated several fungal species from the wheat grain, including Alternaria alternata, Alternaria infectoria, Aspergillus flavus, Epicoccum nigrum and Fusarium poae (2). Among these fungi, Aspergillus and Fusarium spp. are known to produce harmful mycotoxins that can present serious risks not only for the plants, but also for human and animal health (3). Therefore, treatments with fungicides are necessary to protect the plants and/or the harvested crop from spoilage and to reduce the damage. However, the use of synthetic fungicides has led to the development of fungal resistance against antifungal agents and fungicide residues can also be harmful to other organisms (e.g. mammals) (4). Additionally, the awareness of consumers to use, and hence farmers to produce, organic food is rising. For these reasons, the interest in new and more 'green' (i.e. more consumer and nature friendly) bioprotective agents has increased. 
Plant-derived metabolites are an important source of biologically active compounds (5) that can be obtained as extracts and essential oils from a variety of plant species. Among these, there are also invasive alien plant species that can cause problems in new habitats due to their negative impact on the native biodiversity, their effects on human health (e.g. allergenic plants), and their associated economic losses (e.g. infrastructural damage) (6). Regular annual management of such habitats to reduce populations of invasive plants involves organised mowing and/or removal, and therefore large quantities of biomass are readily available. Hence, despite their harmful effects, invasive plants also present a potential source of usable and beneficial compounds. Therefore, in the present study, we tested some invasive members of the Asteraceae family, known as goldenrod (Solidago spp.), and the Polygonaceae family, known as Japanese knotweed (Fallopia japonica (Houtt.) Ronse Decr.).

Goldenrod is a herbaceous perennial that mainly originates in North America. In Europe, it is found as the native species of European goldenrod (Solidago virgaurea L.), which is used in traditional medicine for infections and inflammation of the bladder and kidney. On the other hand, Canadian goldenrod (Solidago canadensis L.) and giant goldenrod (Solidago gigantea Aiton) are invasive weeds that form dense populations along roads, railways and other ruderal habitats (7). As these have similar properties to $S$. virgaurea, they might also have uses as medicinal plants. Goldenrod contains many biologically active compounds, which include flavonoids, triterpene saponins, diterpene lactones, phenolic glycosides, phenolic acids, tannins and essential oils (8). The analyses of these Solidago essential oils in Poland showed high content of terpenes a-pinene, limonene and germacrene D (912). Previous studies of the biological activities of goldenrod had demonstrated mainly antibacterial activities of their extracts (8,13-16) and essential oils (17-19). On the other hand, their potential antifungal activities have been less studied, although inhibition of fungal growth by goldenrod extracts and essential oils has been reported against Aspergillus niger $(16,17)$, Candida albicans $(17,20,21)$, and Armillaria mellea and Fusarium sp. (13).

Japanese knotweed originates in eastern Asia, where it is used in traditional medicine and as food (22). In Europe and North America, it is one of the most invasive alien species. It forms dense populations along rivers, roads and railways. Its success in new habitats is primarily related to vegetative reproduction through underground rhizomes, with high regeneration and rapid growth of large shoots that have broad leaves which overgrow and overshadow the nearby plants (23). Phytochemical studies of the composition of knotweed rhizomes and shoots have indicated high amounts of quinones, stilbenes, flavonoids, coumarins, lignans and other compounds (24). Japanese knotweed is a rich source of resveratrol, which is used as an antioxidant dietary supplement $(25,26)$. Biological activity of Japanese knotweed has been previously shown, mainly as antibacterial activity of the underground tissues, while its antifungal activity has rarely been reported ( 22 and references therein).

Therefore, based on the known biological activities of goldenrod and knotweed and on the availability of a large biomass, we tested the effectiveness of goldenrod and knotweed extracts and goldenrod essential oil against crop-borne pathogenic and saprophytic fungi that the food industry must regularly contend with. In addition, the goldenrod essential oils that showed moderate antifungal activities were tested for effects on germination of wheat grain and on early growth of seedlings.

\section{MATERIALS AND METHODS}

\section{Plant material}

Goldenrod (Solidago spp.) was collected in the flowering period in August from various locations. Fresh shoots of $S$. virgaurea were collected at four locations in Zasavje, Slove-

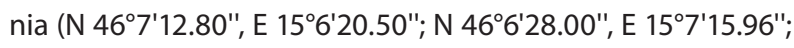
N 46 $9^{\prime} 1.08^{\prime \prime}$, E $14^{\circ} 56^{\prime} 41.82^{\prime \prime}$; and N 46 $8^{\prime} 58.13^{\prime \prime}$, E 14 ${ }^{\circ} 55^{\prime} 40.39^{\prime \prime}$ ), fresh shoots of S. canadensis were collected in Ljubljana, Slovenia (N 46 $\left.4^{\prime} 19.86^{\prime \prime}, \mathrm{E} 14^{\circ} 25^{\prime} 52.25^{\prime \prime}\right)$, and fresh shoots of $S$. gigantea were collected at two locations in Ljubljana, Slovenia ( $46^{\circ} 3^{\prime} 29.44^{\prime \prime}, \mathrm{E} 14^{\circ} 27^{\prime} 50.30^{\prime \prime}$; and N 46 $3^{\prime} 17.61^{\prime \prime}, \mathrm{E}$ $\left.14^{\circ} 27^{\prime} 11.34^{\prime \prime}\right)$. The leaves and flowers were separately removed from the shoots and air dried at room temperature in the dark.

Mature leaves and rhizomes of Fallopia japonica (Houtt.) Ronse Decr. were collected in June and November, respectively, in a dense stand next to the stream Mali Graben in Ljubljana, Slovenia (N 4602'33.9", E 14²7'00.9"). The fresh leaves were separated from the shoots and dried at $60{ }^{\circ} \mathrm{C}$ in a forced ventilation oven (Heraeus Instruments, Hanau, Germany). Fresh rhizomes were washed with tap water, cut into $1-\mathrm{cm}$ thick pieces, frozen in liquid nitrogen, lyophilised (AIpha 1-4LSC; Christ, Osterode am Harz, Germany), and stored at room temperature in the dark.

\section{Preparation of aqueous and organic extracts}

The extracts were prepared as previously described (13). Dry Solidago spp. leaves and flowers were ground in a mill (M20; IKA-Werke, Staufen, Germany), and $50 \mathrm{~g}$ of this ground material were dissolved in $300 \mathrm{~mL}$ distilled water for the aqueous extract, or in $300 \mathrm{~mL} 96 \%$ ethanol for the organic extract. The mixtures were left shaking at $175 \mathrm{rpm}$ for $24 \mathrm{~h}$ at room temperature on an orbital shaker (Laboshake 500; Gerhardt, Königswinter, Germany). After the extraction, the mixtures were vacuum filtered (520A filter paper; Whatman, GE Healthcare Life Sciences, Maidstone, UK) and the solvents were evaporated under reduced pressure at $40^{\circ} \mathrm{C}$ using a rotary flask evaporator (Rotavapor R-124, Vacobox B-177, Waterbath B-480; Büchi, Flavil, Switzerland). These dry crude extracts were stored in sterile glass bottles at room temperature in the dark. 
Dry F. japonica leaves and rhizomes were ground in a mill (M20; IKA-Werke) and $50 \mathrm{~g}$ ground material were dissolved in $600 \mathrm{~mL}$ distilled water for the aqueous extract, or in $300 \mathrm{~mL}$ absolute acetone, methanol or ethanol for the different organic extracts. Dry plant material absorbed more water than organic solvents, therefore higher volume was needed for the aqueous extracts. The mixtures were then processed to the crude extracts as for the Solidago spp. (see above) and stored in sterile glass bottles at room temperature in the dark.

To determine the antifungal activities of these extracts from Solidago spp. and F. japonica, $500 \mathrm{mg}$ of crude extract were resuspended in $1 \mathrm{~mL}$ distilled water or $1 \mathrm{~mL}$ ethanol (for aqueous and organic extracts, respectively). The extracts $\left(\gamma_{\text {final }}=500 \mathrm{mg} / \mathrm{mL}\right)$ were vortexed and stored at $4{ }^{\circ} \mathrm{C}$ until added onto the surface of the fungal growth medium.

\section{Distillation and gas chromatography-mass} spectrometry analysis of goldenrod essential oil

A mixture of $4 \mathrm{~L}$ deionised water with either $200 \mathrm{~g}$ dry Solidago spp. flowers or $300 \mathrm{~g}$ dry Solidago spp. leaves was placed in a 5 -litre round-bottomed flask, and connected to a Clevenger apparatus. The heating was regulated to generate a boiling and condensation speed of $2-3 \mathrm{~mL} / \mathrm{min}$. The boiling time was $4 \mathrm{~h}$. Following complete distillation, the essential oils were collected and the volume measured in a graduated tube of the Clevenger apparatus. Then, the essential oils were carefully separated from the water phase. Yield of essential oil ( $\mathrm{mL} /$ $\mathrm{kg}$ ) was calculated as a ratio between the measured volume of essential oil and the mass of dry plant material used for the distillation. Solutions of essential oil were prepared in hexane ( $\varphi=0.005$; gas chromatography grade; Merck, Darmstadt, Germany) for gas chromatography-mass spectrometry analysis.

A gas chromatograph (GCMS-QP2010 Ultra; Shimadzu, Kyoto, Japan) was used to analyse the material. A fused silica column was used (Rxi-5 Sil MS; $30 \mathrm{~m} \times 0.25 \mathrm{~mm}$ i.d.; film thickness, $0.25 \mu \mathrm{m}$; Restek, Bellefonte, PA, USA). The temperature programme began at $50^{\circ} \mathrm{C}$ for $5 \mathrm{~min}$, and was then raised to $250{ }^{\circ} \mathrm{C}$ at $3{ }^{\circ} \mathrm{C} / \mathrm{min}$, and then held at $250{ }^{\circ} \mathrm{C}$ for $5 \mathrm{~min}$. The injection temperature was $250^{\circ} \mathrm{C}$, the temperature of the ion source was $200^{\circ} \mathrm{C}$, and the temperature of the interface was $270^{\circ} \mathrm{C}$. The injection volume was $1 \mu \mathrm{L}$, the split ratio $1: 100$, the carrier gas $\mathrm{He}$, and the flow $1 \mathrm{~mL} / \mathrm{min}$ linear velocity. The mass spectrometry conditions included electron impact mode at an ionisation voltage of $70 \mathrm{eV}$, with total ion current recorded, and a scan range from 35 to $500 \mathrm{~m} / \mathrm{z}$ at a frequency of $5 \mathrm{~Hz}$. The detector voltage was $1 \mathrm{kV}$. The total analysis time was $76.7 \mathrm{~min}$.

The compounds were first identified by comparing their mass spectra and retention indices to the spectra and retention indices from the Flavors and Fragrances of Natural and Synthetic Compounds spectral library (27) and National Institute of Standards and Technology spectral library (28). Their identities were then confirmed by comparing them with mass spectra and retention indices of the reference compounds from Sigma-Aldrich, Merck (Steinheim, Germany) for the following compounds: bornyl acetate, caryophyllene oxide, $p$-cymene, limonene, myrcene, $a$-pinene, and $\beta$-pinene. Retention indices were calculated logarithmically with reference to $n$-alkanes as described previously $(9,11)$. Concentrations were calculated as relative peak areas.

\section{Antifungal activities}

The antifungal activities of the Solidago spp. and F.japonica extracts and the Solidago spp. essential oils were tested against five moulds: A. alternata, A. infectoria, A. flavus, E. nigrum and $F$. poae. These fungi were previously isolated from wheat grain and identified by molecular methods (2). The majority of these fungal isolates are saprophytic, and A. flavus and $F$. poae are considered to be plant pathogens.

The inhibitory effects of the Solidago spp. and F.japonica extracts on radial growth of the fungal mycelia were tested following the method described in our previous study (13). A volume of $50 \mu \mathrm{L}$ of aqueous or organic extract ( $\gamma=500 \mathrm{mg}$ / $\mathrm{mL}$ ) was spread over each Petri dish $(d=90 \mathrm{~mm}$ ) containing potato dextrose agar ( 0.02 mass per volume ratio; Biolife, $\mathrm{Mi}$ lano, Italy) using a Drigalski spatula. Disks of fungal mycelia ( $d=5 \mathrm{~mm}$ ) were cut from the margins of 7-day-old stock cultures and aseptically inoculated by placing them in the centre of the medium with the extract. Control samples without extracts (for aqueous extracts) and with ethanol (for organic extracts) were prepared at the same time. Fungicide azoxystrobin $(10 \mathrm{mg} / \mathrm{mL})$ was used as the standard reference for antifungal activity. The fungal colonies were incubated at room temperature $\left((23 \pm 2){ }^{\circ} \mathrm{C}\right)$ in the dark for 7 days.

The inhibitory effects of the Solidago spp. essential oils on radial growth of the fungal mycelia were tested using the agar dilution method, similar to that described by Zabka et al. (29) and in our previous studies (2,30). The pure essential oils were added to the autoclaved potato dextrose agar medium (Biolife) at approx. $40^{\circ} \mathrm{C}$ to prepare the final volume fractions of essential oils $\varphi=0.001,0.0005$ and 0.0001 . The medium was poured in the Petri dish $(d=90 \mathrm{~mm})$ and left to solidify. Control samples without essential oil were prepared at the same time. Disks of fungal mycelia $(d=5 \mathrm{~mm})$ were cut from the margins of 7-day-old stock cultures and aseptically inoculated by placing them in the centre of the medium. Petri dishes were sealed with parafilm to prevent evaporation of the essential oil. The fungal colonies were incubated at room temperature $\left((23 \pm 2)^{\circ} \mathrm{C}\right)$ in the dark for 7 days.

Inhibition of the fungal radial growth was calculated according to Lira-De León et al. (5):

$$
\begin{gathered}
\text { Inhibition }=((d \text { (control colonies })-d(\text { treated colonies })) / \\
d(\text { control colonies }) \cdot 100
\end{gathered}
$$

where $d$ is the mean diameter of the fungal colony. Three replicates were carried out for each treatment.

\section{Germination and fungal contamination of wheat grain}

Wheat (Triticum aestivum) grain from the Vila Natura ecological farm (Vučja vas, Prlekija, Slovenia) was used to evaluate 
the fungicidal activities of the Solidago spp. essential oils. Non-sterile wheat grain (10 g) was treated with Solidago spp. essential oils $(\varphi=0.02)$ prepared by dilution of the concentrated essential oils in dimethylsulphoxide $(\varphi=0.1)$, as described by Anžlovar et al. (2). The grains were submerged and incubated in the essential oils in Petri dishes sealed with parafilm and under shaking $(50 \mathrm{rpm})$ at $(25 \pm 2){ }^{\circ} \mathrm{C}$ for $24 \mathrm{~h}$. The control grains were soaked in dimethylsulphoxide $(\varphi=0.1)$, also with shaking.

After the treatments with the essential oils, fungal infection and seed germination were quantified using the direct plating method (2). Following the treatments, 10 subsamples of 10 wheat grains were placed on potato dextrose agar $(0.02$ mass per volume ratio) in Petri dishes $(d=90 \mathrm{~mm})$ and incubated at $(25 \pm 2){ }^{\circ} \mathrm{C}$ in the dark. The development of fungal colonies on the surface of the wheat grain was monitored daily, and after $74 \mathrm{~h}$ the fungal infections were quantified by counting the number of infected grains, expressed as a percentage of the total used grains. At the same time, the germination of the wheat grain was examined by counting the number of germinated grains, again expressed as a percentage of the total used grains.

\section{Statistical analysis}

For the antifungal activities, three fungal colonies per treatment were measured and mean values were calculated. From these data, inhibition of fungal growth was calculated. Mean values and standard errors were calculated for the fungal infection and germination of the wheat grain treated with essential oils ( $N=10$ per treatment).

The significance $(p<0.05)$ of the differences between the treated and control samples in antifungal and germination experiments was tested using one-way ANOVA and Tukey's post-hoc tests. Statistical analysis was performed using the Prism v. 5.01 software (31).

\section{RESULTS AND DISCUSSION}

This study was conducted to evaluate the potential of extracts from the invasive plants goldenrod and knotweed, and the essential oils from goldenrod, as antifungal and preservative agents against five fungal species that were previously isolated from wheat grain (2), each with the potential for crop spoilage. These fungal species inhabit different ecological niches where they function as saprophytes and/or pathogens: $A$. alternate and $A$. infectoria as endophytes/saprophytes, $A$. flavus as a saprophyte/pathogen, $E$. nigrum as a saprophyte, and $F$. poae as a pathogen. Solidago spp. and F. japonica extracts and Solidago spp. essential oils were prepared separately from the leaves, rhizomes and/or flowers and were spread over the fungal growth medium. The data show the greatest antifungal activities for the Solidago spp. essential oils, although the Solidago spp. leaf and flower extracts and the $F$. japonica rhizome extracts also have promising potential for antifungal treatments.

\section{Composition of the Solidago spp. essential oils}

Data on the yields of the Solidago spp. essential oils and their chemical composition (Table 1) show that S. canadensis yielded higher amounts of essential oils than S. gigantea and S. virgaurea, and for all three of these species the essential oils yield from flowers was higher than from leaves. Similarly, a higher amount of essential oils was found in the flowers than in other aerial parts of $S$. canadensis (32). The essential oil of S. virgaurea had the highest number of tentatively identified compounds.

Table 1. Composition of flower and leaf essential oils from S. canadensis, S. gigantea and S. virgaurea. For each of the essential oils, the five compounds showing the highest levels for the relative peak areas are given in italic

\begin{tabular}{|c|c|c|c|c|c|c|c|c|c|}
\hline \multirow{3}{*}{ Compound } & \multirow{3}{*}{ Identification } & \multirow{2}{*}{\multicolumn{2}{|c|}{ RI }} & \multicolumn{6}{|c|}{ Relative peak area for essential oil/\% } \\
\hline & & & & \multicolumn{2}{|c|}{ S. canadensis } & \multicolumn{2}{|c|}{ S. gigantea } & \multicolumn{2}{|c|}{ S. virgaurea } \\
\hline & & Database & Measured & Flower & Leaf & Flower & Leaf & Flower & Leaf \\
\hline \multicolumn{10}{|l|}{ Terpenes and terpenoids } \\
\hline a-Pinene & $\mathrm{MS}, \mathrm{RC}, \mathrm{RI}$ & 933 & 931 & 33.1 & 2.7 & 7.6 & 1.8 & 28.5 & 13.1 \\
\hline$\beta$-Pinene & $\mathrm{MS}, \mathrm{RC}, \mathrm{RI}$ & 978 & 974 & 2.6 & 0.7 & 1.0 & 0.4 & 4.6 & 2.7 \\
\hline Myrcene & $\mathrm{MS}, \mathrm{RC}, \mathrm{RI}$ & 991 & 988 & 1.0 & 0.2 & 0.7 & 0.6 & 5.1 & 2.3 \\
\hline Limonene & $\mathrm{MS}, \mathrm{RC}, \mathrm{RI}$ & 1030 & 1027 & 21.5 & 2.8 & 1.0 & 0.8 & 3.6 & 2.8 \\
\hline Bornyl acetate & $\mathrm{MS}, \mathrm{RC}, \mathrm{RI}$ & 1285 & 1282 & 3.8 & 5.5 & 4.1 & 9.1 & 1.2 & 1.5 \\
\hline a-Gurjunene & MS, RI & 1406 & 1406 & 0.8 & 2.9 & 4.4 & nd & 0.1 & 3.0 \\
\hline a-Humulene & MS, RI & 1454 & 1454 & 0.4 & 0.4 & 0.4 & 0.4 & 4.9 & 4.3 \\
\hline Y-Muurolene & MS, RI & 1478 & 1474 & nd & 0.2 & 1.3 & 2.0 & 0.3 & 0.3 \\
\hline Germacrene D & MS, RI & 1480 & 1479 & 10.4 & 48.7 & 20.8 & 33.8 & 8.4 & 6.3 \\
\hline$\delta$-Cadinene & MS, RI & 1518 & 1517 & 0.3 & 0.4 & 1.5 & 2.3 & 1.6 & 1.5 \\
\hline Spathulenol & MS, RI & 1576 & 1574 & 1.4 & 2.0 & 2.3 & 2.4 & 2.0 & 6.5 \\
\hline Caryophyllene oxide & $\mathrm{MS}, \mathrm{RC}, \mathrm{RI}$ & 1587 & 1579 & 1.1 & 1.2 & 1.9 & 1.2 & 4.8 & 10.2 \\
\hline Humulene epoxide II & MS, RI & 1613 & 1607 & 0.3 & 0.4 & 0.6 & 0.5 & 3.1 & 6.7 \\
\hline Cyclocolorenone & MS, RI & 1757 & 1749 & 0.6 & 7.6 & 3.3 & nd & nd & nd \\
\hline \multicolumn{10}{|l|}{ Aromatic compounds } \\
\hline p-Cymene & $\mathrm{MS}, \mathrm{RC}, \mathrm{RI}$ & 1025 & 1022 & 0.9 & 0.1 & 3.6 & 0.2 & 0.2 & 0.3 \\
\hline$Y($ essential oil)/(mL/kg) & & & & 8.3 & 5.5 & 2.0 & 1.2 & 1.8 & 1.0 \\
\hline
\end{tabular}

$\mathrm{MS}=$ mass spectrum, $\mathrm{RC}=$ reference compound, $\mathrm{Rl}=$ retention index, $\mathrm{Y}=\mathrm{yield}$, nd=not detected 
In all of the samples, terpenes and terpenoids were the major components, although the compositions differed according to the Solidago spp. and the plant tissue used for the preparation of the essential oils (Table 1). The data available in the literature generally relate to the composition of $S$. canadensis essential oils. The major components of essential oils from S. canadensis shoots and flowers have been reported as a-pinene and germacrene D (12), and as a-pinene, germacrene $D$ and (E)-nerolidol (33). For S. canadensis flowers more specifically, the major constituents of the essential oils have been reported as $a$-pinene, $\gamma$-cadinene and limonene (10) and as a-pinene, germacrene D and curlone (34). The main constituent of essential oils from $S$. canadensis roots is thymol (17). In the present study, the major constituents of essential oils from $S$. canadensis flowers were a-pinene, limonene, germacrene $D$, bornyl acetate and $\beta$-pinene, while those from S. canadensis leaves were germacrene $D$, cyclocolorenone, bornyl acetate, a-gurjunene and limonene (Table 1 and Fig. S1), which are generally comparable to the data published by Kalemba et al. $(10,12)$.

The $S$. gigantea flowers yielded the five main constituents of essential oils: germacrene D, a-pinene, a-gurjunene, bornyl acetate and $p$-cymene, while for the leaves these were germacrene $D$, bornyl acetate, spathulenol, khusinol and $\delta$-cadinene (Table 1 and Fig. S2). This composition is similar to the results of Kalemba et al. (11) and Kalemba and Thiem (12) who reported also the content of cyclocolorenone up to $35 \%$. In our study this content was lower, around $3 \%$ in the flower essential oil while in leaves it was not detected. The essential oil of native species S. virgaurea (Table 1 and Fig. S3) contained $a$ - and $\beta$-pinene, myrcene and caryophyllene oxide, which is similar to the studies of Kalemba et al. (9), and a-humulene and germacrene $D$ as reported by Kalemba and Thiem (12). The five major components in S. virgaurea flower essential oils were $a$-pinene, germacrene $D$, myrcene, $a$-humulene and caryophyllene oxide, while in the leaves these were a-pinene, caryophyllene oxide, humulene epoxide II, spathulenol and germacrene D.

A comparison of the essential oil compositions across all of these samples shows that germacrene $D$ is the most frequently found as one of the top five components, followed by a-pinene and bornyl acetate. S. virgaurea stands out here too, with high proportions of caryophyllene oxide, humulene epoxide, spathulenol and a-humulene in both the flower and leaf essential oils, with myrcene also in the flower essential oils, along with some compounds that were not found in the other Solidago spp.: benzoates, benzyl salicylate and ketones. The S. canadensis flower and leaf essential oils and the S. gigantea flower essential oils had relatively high proportions of limonene, cyclocolorenone and $p$-cymene, respectively. The S. canadensis leaf essential oils and the S. gigantea flower essential oils stand out too, as they both showed relatively high proportions of a-gurjunene. Grul'ová et al. (35) report about remarkable variations in the chemical composition of essential oils of invasive goldenrod populations among collection areas both within the same species (S. canadensis) and between the two species (S. canadensis and S. gigantea). These results and previous studies combined thus indicate that the composition of Solidago essential oils is highly variable. However, in most cases, direct comparisons should be made with care, as the essential oils were not always distilled from the flowers and leaves separately.

\section{Antifungal activities of the extracts and essential oils}

The antifungal activities of the Solidago spp. and F. japonica extracts were tested using the spread plate method against the five fungal species. These fungi were differentially susceptible to the plant extracts, although in general the Solidago spp. extracts were more effective than the $F$. japonica extracts, and the organic extracts were more effective than the aqueous extracts.

Overall, the extracts from all three Solidago spp. showed similar inhibition of fungal growth (22-25\%), with no significant differences among the species $(p=0.8775)$. The extracts of $S$. canadensis provided a maximum of $61.8 \%$ inhibition, $S$. gigantea of $47.1 \%$, and S. virgaurea of $56.9 \%$, with all of these maxima obtained against F. poae (Table 2). Between the extracts in terms of the two plant tissues (i.e. leaves, flowers) and in terms of the two solvents (i.e. water, ethanol), there were no significant differences for this inhibition of fungal growth $(p=0.6394 ; p=0.1769$; respectively).

The susceptibilities of the fungal species to the Solidago spp. extracts from the most to the least were: F. poae (mean growth inhibition calculated from the data in Table $2(40.9 \pm 14.7) \%)>E$. nigrum $((33.3 \pm 9.9) \%)>A$. alternata $((27.9 \pm 12.0) \%)>A$. flavus $((9.6 \pm 5.8) \%)>A$. infectoria $((4.6 \pm 4.8)$ $\%)$. These data show that the leaves and/or flowers of all three Solidago spp. could indeed be used as antifungal treatments. These data also indicate the wide range of fungal growth inhibition obtained for these Solidago spp. extracts. Webster et al. (36) tested an aqueous extract of S. gigantea and also reported moderate antifungal activity against some pathogens and moulds, but not against $A$. flavus.

Higher antifungal activities might instead be predicted for extracts from the underground plant tissues (i.e. roots), because these generally contain higher amounts of biologically active compounds such as rutin, catechin, epicatechin, and chlorogenic and ferulic acids, and others (13). In the present study, we used the above-ground shoots because they are regularly harvested to maintain the infrastructure and to control invasive plants, thus potentially providing a large biomass.

Fallopia japonica is less aromatic than these Solidago spp., although it is a well-known and rich source of biologically active compounds (e.g. resveratrol, catechin, and others), with higher amounts reported for the underground tissues $(22,26)$. It is a very invasive species, and one of the best ways to eradicate the plants and to control their distribution is regular mechanical cutting of the shoots and/or digging out the below-ground parts combined with chemical treatments (37). 
Table 2. Antifungal activities of the leaf and flower aqueous and ethanol extracts of the Solidago spp. The inhibition of fungal growth was calculated from the mean $(N=3)$ diameters of the fungal colonies for the control and extracts

\begin{tabular}{|c|c|c|c|c|c|c|}
\hline \multirow{2}{*}{ Source } & \multirow{2}{*}{ Extract } & \multicolumn{5}{|c|}{ Growth inhibition/\% } \\
\hline & & A. alternata & A. infectoria & A. flavus & E. nigrum & F. poae \\
\hline \multicolumn{7}{|l|}{ S. canadensis } \\
\hline \multirow[t]{2}{*}{ Leaf } & Aqueous & 50.08 & -0.27 & 22.20 & 33.63 & 39.82 \\
\hline & Ethanol & 26.42 & 13.96 & 6.38 & 22.20 & 55.25 \\
\hline \multirow[t]{2}{*}{ Flower } & Aqueous & 37.24 & -0.07 & 11.14 & 19.72 & 29.80 \\
\hline & Ethanol & 27.43 & 7.54 & 3.53 & 29.85 & 61.76 \\
\hline \multicolumn{7}{|l|}{ S. gigantea } \\
\hline \multirow[t]{2}{*}{ Leaf } & Aqueous & 17.94 & -0.95 & 16.68 & 19.28 & 40.75 \\
\hline & Ethanol & 38.53 & 9.24 & 7.62 & 46.43 & 47.12 \\
\hline \multirow[t]{2}{*}{ Flower } & Aqueous & 20.15 & 0.33 & 5.89 & 42.45 & 22.40 \\
\hline & Ethanol & 37.81 & 4.64 & 2.11 & 40.46 & 29.91 \\
\hline \multicolumn{7}{|l|}{ S. virgaurea } \\
\hline \multirow[t]{2}{*}{ Leaf } & Aqueous & 12.21 & 3.30 & 9.45 & 34.31 & 17.17 \\
\hline & Ethanol & 33.00 & 9.72 & 13.88 & 32.38 & 55.75 \\
\hline \multirow[t]{2}{*}{ Flower } & Aqueous & 8.83 & 1.12 & 11.15 & 48.61 & 33.59 \\
\hline & Ethanol & 25.66 & 6.61 & 5.58 & 29.90 & 56.94 \\
\hline Azoxystrobin & & 43.32 & 47.12 & 94.75 & 63.50 & 69.24 \\
\hline
\end{tabular}

Negative numbers indicate growth stimulation

For this reason, we prepared $F$. japonica extracts from leaves and rhizomes separately in water and in different organic solvents. The data on these antifungal activities show that the rhizome extracts inhibited fungal growth more effectively than the leaf extracts $(p=0.0182)$ (Table 3$)$. Indeed, the leaf extracts not only had lower antifungal activities, but they also even stimulated the growth of $A$. alternata, E. nigrum and $F$. poae. This beneficial effect might be related to fungal hormesis, which is when fungi positively react to low concentrations of specific compounds that stimulate their growth (38). On the other hand, the choice of extraction solvent did not significantly affect the antifungal activities of these $F$. japonica extracts $(p=0.2982)$. Here, the ethanol and methanol extracts were generally the most effective, while being similar, followed by the acetone extracts, with the aqueous extracts as the least effective. The higher activities of the ethanol extracts might be related to the higher content of phenolic compounds, which are extracted better in polar solvents like ethanol and methanol (39).
The susceptibilities of the fungal species to the most effective $F$. japonica extracts (i.e. rhizome with methanol and ethanol) were as follows, from most susceptible to least (calculated from the data in Table 3): E. nigrum ((74.4 \pm 3.4$) \%)>A$. infectoria $((63.9 \pm 8.1) \%)>F$. poae $((57.5 \pm 3.2) \%)>A$. alternata

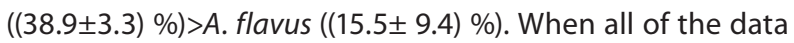
on the growth inhibition are taken into account, the means are lower and the order of the fungal susceptibilities is different: $A$. infectoria $>$ A. flavus $>$ E. nigrum $>$ A. alternata $>$ F. poae. Although antifungal activities of $F$.japonica extracts have rarely been reported, Peng et al. (22) defined inhibitory effects for Trichophyton rubrum, Microsporum gypseum, Fonsecaea pedrosi and Candida albicans.

In addition to these Solidago spp. and F.japonica extracts, the antifungal activities were also investigated for the Solidago spp. essential oils against the same five fungal species, and here three different volume fractions were used to determine whether these activities are concentration dependent. The inhibition of fungal growth by essential oils and extracts can

Table 3. Antifungal activities of the aqueous and organic leaf and rhizome extracts of $F$. japonica. The inhibition of the fungal growth was calculated from the mean $(N=3)$ diameters of the fungal colonies for the control and extracts

\begin{tabular}{lcccccc}
\multirow{2}{*}{ Source } & Extract & \multicolumn{5}{c}{ Growth inhibition/\% } \\
\cline { 3 - 7 } Leaf & Aqueous & -29.46 & 1.15 & 82.15 & -15.57 & -59.09 \\
& Acetone & -29.17 & 19.62 & 17.83 & -27.10 & -103.96 \\
& Methanol & -46.93 & 23.19 & 11.72 & -35.59 & -71.14 \\
\multirow{3}{*}{ Rhizome } & Ethanol & -56.83 & 37.43 & 16.08 & -34.51 & 61.56 \\
& Aqueous & -0.19 & -9.27 & -7.99 & 25.11 & -49.61 \\
& Acetone & 27.52 & 19.12 & 7.26 & 54.02 & -10.85 \\
& Methanol & 41.23 & 58.18 & 8.85 & 76.83 & 55.22 \\
& Ethanol & 36.61 & 69.60 & 22.18 & 71.96 & 59.73 \\
\hline
\end{tabular}

Negative numbers indicate growth stimulation 
not be directly compared due to different extraction methods and concentrations but generally the essential oils have higher activity than extracts, as shown here and by others (40). The highest volume fraction $(\varphi=0.001)$ of Solidago spp. essential oils generally showed the greatest inhibition of fungal growth across these treatments. However, for A. infectoria treated with $S$. canadensis leaf essential oils and S. virgaurea flower essential oils, and E. nigrum and F. poae treated with S. gigantea flower essential oils, the lower volume fraction of $\varphi=0.0005$ essential oils showed greater inhibition than $\varphi=0.001$ (Table 4).

The essential oils of S. virgaurea and S. gigantea showed greater inhibition (calculated from the data in Table 4; $(60.8 \pm 13.1)$ and $(60.7 \pm 11.5) \%$, respectively) than those of $S$. canadensis ((51.4 \pm 13.0$) \%)$, although this difference did not reach statistical significance $(p=0.1928)$. The antifungal activities were similar when essential oils from leaves and flowers were used $(p=0.3598)$, which is in agreement with the similar chemical compositions of these tested essential oils ( Table 1). The susceptibility of the fungal species to the essential oils were as follows, from most susceptible to least: $E$. nigrum $((70.2 \pm 3.9) \%)>A$. infectoria $((64.3 \pm 15.0) \%)>F$. poae $((61.2 \pm 7.08)$ $\%)>A$. flavus ((46.8 \pm 6.6$) \%)>A$. alternata ((45.2 \pm 7.3$) \%)$. Solidago spp. essential oils have been tested previously mainly in terms of their antibacterial activities, while antifungal treatments are rare, and different effects have been reported. Essential oils from $S$. canadensis roots showed mild to moderate inhibition of growth of $A$. niger and C. albicans, respectively (17), while essential oils from $S$. canadensis leaves did not inhibit human pathogenic fungi (18) but showed promising antifungal activity against $M$. fructicola at mass concentration $1000 \mathrm{~g} / \mathrm{mL}$, which was significantly higher than of Azoxystrobin $(\varphi=0.001)$. On the other hand only the moderate activity was observed against $A$. niger and no activity against $B$. cinerea (41). In the present study, however, we show concentration-dependent inhibitory effects for the leaf and flower essential oils on all five of these seed-associated fungi. For this reason, whole Solidago spp. shoots can be used to produce these essential oils, without the need to separate leaves and flowers. According to the composition of essential oils and the results of antifungal activity, it is most likely that the major components germacrene $\mathrm{D}$, a-pinene and bornyl acetate are also the most responsible for the reduction of fungal growth. However, other compounds even in smaller amounts can affect growth too due to the sinergistic effects $(40,42)$. The same wheat-borne fungi were used in our previous study with thyme essential oil (2). The comparison of antifungal activities of goldenrod and thyme essential oils shows that Solidago oil has lower antifungal activity than thyme. Nevertheless, the biomass of goldenrod is much higher than of thyme, therefore further studies of more effective preparations should be continued, also with other harmful organisms.

The treatments with these essential oils also resulted in bleaching of $A$. flavus mycelia, as these changed colour from green in controls to yellow, and even white, when the highest concentrations of the essential oils were applied (data not shown). Such colour changes of the mycelia might correspond to reduced virulence (43).

Table 4. Antifungal activities of Solidago spp. essential oils prepared from the three species and for two tissues. The inhibition of the fungal growth was calculated from the mean $(N=3)$ diameters of the fungal colonies for the control and extracts

\begin{tabular}{|c|c|c|c|c|c|c|}
\hline \multirow{2}{*}{$\begin{array}{l}\text { Essential oil } \\
\text { source }\end{array}$} & \multirow{2}{*}{$\begin{array}{l}\varphi \text { (essential } \\
\text { oil) }\end{array}$} & \multicolumn{5}{|c|}{ Growth inhibition/\% } \\
\hline & & A. alternata & A. infectoria & A. flavus & E. nigrum & F.poae \\
\hline \multicolumn{7}{|l|}{ S. canadensis } \\
\hline \multirow[t]{3}{*}{ Leaf } & 0.0010 & 39.1 & 39.8 & 45.3 & 68.3 & 56.7 \\
\hline & 0.0005 & 31.1 & 52.2 & 21.6 & 59.6 & 54.4 \\
\hline & 0.0001 & 13.0 & 23.0 & 8.0 & 17.0 & 48.0 \\
\hline \multirow[t]{3}{*}{ Flower } & 0.0010 & 39.1 & 66.1 & 35.5 & 66.6 & 57.9 \\
\hline & 0.0005 & 28.9 & 34.3 & 19.6 & 43.9 & 50.9 \\
\hline & 0.0001 & 0.0 & 23.0 & 3.0 & 3.0 & 40.0 \\
\hline \multicolumn{7}{|l|}{ S. gigantea } \\
\hline \multirow[t]{3}{*}{ Leaf } & 0.0010 & 48.6 & 69.9 & 49.2 & 74.2 & 64.6 \\
\hline & 0.0005 & 42.2 & 64.2 & 41.2 & 64.9 & 59.6 \\
\hline & 0.0001 & 20.0 & 34.0 & 8.0 & 63.0 & 44.0 \\
\hline \multirow[t]{3}{*}{ Flower } & 0.0010 & 50.0 & 77.4 & 47.2 & 67.7 & 58.4 \\
\hline & 0.0005 & 40.0 & 64.2 & 43.1 & 68.4 & 59.6 \\
\hline & 0.0001 & 20.0 & 24.0 & 3.0 & 56.0 & 41.0 \\
\hline \multicolumn{7}{|l|}{ S. virgaurea } \\
\hline \multirow[t]{3}{*}{ Leaf } & 0.0010 & 55.8 & 78.5 & 55.8 & 76.0 & 74.2 \\
\hline & 0.0005 & 40.0 & 59.7 & 40.0 & 63.2 & 68.4 \\
\hline & 0.0001 & 18.0 & 22.0 & 18.0 & 49.0 & 51.0 \\
\hline \multirow[t]{3}{*}{ Flower } & 0.0010 & 38.4 & 53.8 & 47.9 & 68.3 & 55.6 \\
\hline & 0.0005 & 28.9 & 63.4 & 28.9 & 52.6 & 49.1 \\
\hline & 0.0001 & 0.0 & 18.0 & 10.0 & 14.0 & 49.0 \\
\hline
\end{tabular}




\section{Fungal infection and germination of wheat grain}

Currently, natural protective agents are getting more attention due to their biodegradability and lower toxicity for humans and the environment, compared to synthetic agents. The presence and growth of fungi in and on cereal grain can have devastating effects on the quality and quantity of a harvest, and some fungal contaminations present danger for human health due to their production of mycotoxins. Therefore, the positive results in these analyses of the antifungal activities of the Solidago spp. essential oils can be applied to their use as potential fungicidal agents or preservatives, as has been shown for $S$. canadensis essential oils and postharvest strawberry preservation against Botrytis cinerea (44).

In the present study, the potential of these Solidago spp. essential oils for antifungal treatments of wheat grain was tested. The fungal infections of the grain and the germination rates were monitored for these unsterilised wheat grain, using the same material that was used for previous isolation of fungi. After the treatment with essential oils $(\varphi=0.02)$, the grains were monitored for 3 days. The first fungal infections were observed one day following germination, although only in the grain with the control treatment. On the second day, fungal infections also occurred on 28 to $59 \%$ of the treated grain (data not shown). These infections further increased on the third day, to 43 to $63 \%$. Nevertheless, the treatments of the wheat grain with these Solidago spp. essential oils significantly reduced the fungal infections compared to the untreated controls, with infection rates for the controls of up to $83 \%$ (Fig. 1a).

After 3 days, the lowest fungal infections were observed for the treatments with the S. gigantea essential oils ((44.5 \pm 14.7$) \%)$, followed by S. virgaurea ((58.5 \pm 15.0$) \%)$ and S. canadensis ((62.5 \pm 10.2$) \%)$. These differences were significant only for the S. gigantea essential oils ( $p=0.005$ vs S. virgaurea; $\mathrm{p}<0.0001$ vs S. canadensis). On the other hand, the differences among these essential oils due to the tissues used (i.e. leaves, flowers) did not show significance $(p=0.8032)$.

In addition, the germination rates of these wheat grains were monitored for 3 days, to determine the influence of the Solidago spp. essential oils on seed germination and the early growth of the seedlings (Fig. 1b). All of these Solidago spp. essential oils significantly decreased wheat germination, except for those from the leaves of S. canadensis. For S. virgaurea and S. gigantea, the essential oils from leaves inhibited germination more than those from flowers $(p<0.0001$ and $p=0.1769$, respectively). On average, the highest germination rates were seen for wheat grain treated with S. canadensis essential oils

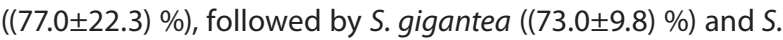
virgaurea ((50.5 \pm 23.7$) \%)$.

Phytotoxic effects of essential oils are well known, and have been reported previously for many plant species, including S. canadensis (45). Essential oils have also been proposed as allelopathic bioherbicides because they effectively inhibit the germination of weed seeds (46-48). In the present study, all of these essential oils except for those from leaves a)

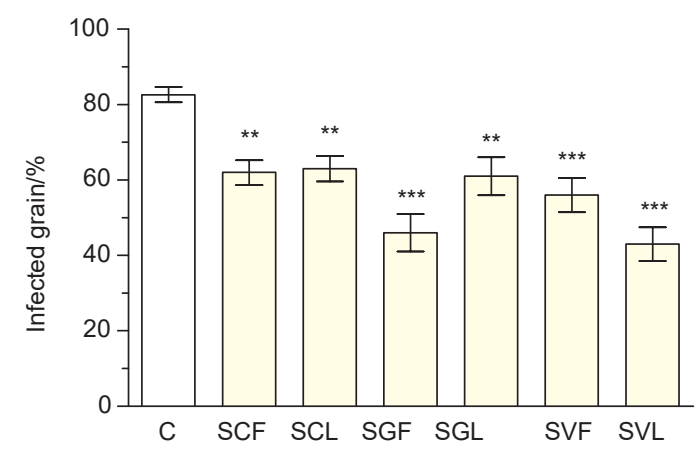

b)

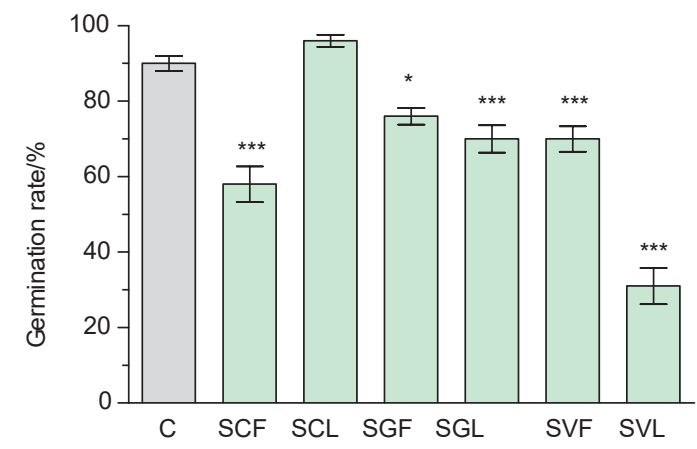

Fig. 1. Fungal infection (a) and germination rates (b) of the wheat grain 3 days after the treatments with Solidago spp. essential oils $(\varphi=0.02)$. $C=$ control, $S C F=S$. canadensis flowers, $S C L=S$. canadensis leaves, $\mathrm{SGF}=\mathrm{S}$. gigantea flowers, $\mathrm{SGL}=\mathrm{S}$. gigantea leaves, $\mathrm{SVF}=\mathrm{S}$. virgaurea flowers, $S V L=S$. virgaurea leaves. Data present mean values $\pm \mathrm{S}_{N}(N=3) ; \mathrm{S}_{N}=$ uncorrected sample standard deviation. Statistical analysis: ${ }^{*} \mathrm{p}<0.05,{ }^{* *} \mathrm{p}<0.01,{ }^{* * *} \mathrm{p}<0.001$

of S. canadensis significantly reduced germination rates of these wheat grain. In combination with the data on the fungal contamination, we can conclude that these Solidago spp. essential oils have the potential to preserve the wheat grain after harvest. On the other hand, the comparable protection against fungal contamination and the higher germination rates for the wheat grain treated with the $S$. canadensis leaf essential oils suggest that this treatment could be used for grain intended for sowing, and thus especially in organic farming, where the use of synthetic preservatives is not allowed. However, the main obstacle for using essential oils as food preservatives is that they interact with food components and other antimicrobial compounds, and when added in high, active amounts cause negative organoleptic effects (40). For these reasons, new antimicrobial blends with components with synergistic effects have been suggested to improve the antimicrobial effects of essential oils. Additional attention should be addressed to different modes of application of essential oils. In contrast to direct treatment of grains, indirect treatment (i.e. fumigation) with Solidago essential oil would diminish negative organoleptic effects. Previously we showed the potential of this indirect application for the thyme essential oil (2). The fumigation with this 
oil reduced fungal infections of wheat grain while germination rate remained high, suggesting that this method can be used in storage containers to protect grain intended for sowing and food production. When the same fungal species and wheat grain were treated previously with thyme essential oils $(2,30,49)$, these had greater effects on fungal growth and seed germination than the goldenrod essential oils in the present study. However, the key potential of goldenrod arises from the large biomass availability, from which essential oils and/ or extracts can be produced and used to provide more ecologically friendly fungicides.

\section{CONCLUSIONS}

The present study has shown that the invasive Canadian goldenrod (Solidago canadensis) and giant goldenrod (S. gigantea) can be used for production of extracts and essential oils that have promising antifungal activities against some of the moulds that are associated with wheat crops. The selection of goldenrod material (i.e. in terms of species and tissue) for distillation of these essential oils had no significant impact on the antifungal activities, and therefore whole shoots can be used for their production. Japanese knotweed (Fallopia japonica) extracts, however, showed antifungal activities only when prepared from the rhizomes, as those prepared from the leaves did not have any activity. Organic extractions with ethanol and methanol are more effective than aqueous extractions. The results of the study indicate that wheat grain could be soaked in or fumigated with Solidago essential oils to protect it against fungal infections.

\section{ACKNOWLEDGEMENTS}

The authors are thankful to Maja Jankovec, Saša Hladnik and Erika Gioahin for technical assistance, and to Chris Berrie for valuable comments and English editing.

\section{FUNDING}

This study was supported by the Slovenian Research Agency (grant no. P1-0212).

\section{CONFLICT OF INTEREST}

The authors declare no conflict of interest.

\section{SUPPLEMENTARY MATERIALS}

All supplementary materials are available at: www.ftb. com.hr.

\section{AUTHORS' CONTRIBUTION}

S. Anžlovar contributed to conception and design of the antifungal testing, data collection, data analysis and interpretation, performing the analysis of fungal growth inhibition and germination, drafting the article, critical revision and final approval of the version to be published. D. Janeš contributed to conception and design of the GC-MS, data collection, data analysis and interpretation, performing the GC-MS analysis, drafting the article, critical revision and final approval of the version to be published. J. Dolenc Koce contributed to conception and design of the antifungal testing, statistical analysis and interpretation, performing the statistical analysis of fungal growth inhibition and germination, drafting the article, critical revision and final approval of the version to be published.

\section{ORCID ID}

S. Anžlovar @i https://orcid.org/0000-0001-8080-6167

D. Janeš @ i https://orcid.org/0000-0003-0930-3422

J. Dolenc Koce 다 https://orcid.org/0000-0002-5454-4842

\section{REFERENCES}

1. Ghosh T, Biswas MK, Guin C, Roy P, Aikat K. A review on seed borne mycoflora associated with different cereal crop seeds and their management. PCBMB. 2018;19(3-4):107-17.

2. Anžlovar S, Likar M, Dolenc Koce J. Antifungal potential of thyme essential oil as a preservative for storage of wheat seeds. Acta Bot Croat. 2017;76(1):64-71.

https://doi.org/10.1515/botcro-2016-0044

3. Zain ME. Impact of mycotoxins on humans and animals. J Saudi Chem Soc. 2011;15(2):129-44.

https://doi.org/10.1016/j.jscs.2010.06.006

4. Brauer VS, Rezende CP, Pessoni AM, De Paula RG, Rangappa KS, Nayaka SC, et al. Antifungal agents in agriculture: Friends and foes of public health. Biomolecules. 2019;9(10):521.

https://doi.org/10.3390/biom9100521

5. Lira-De León KI, Ramírez-Mares MV, Sánchez-López V, Ramírez-Lepe M, Salas-Coronado R, Santos-Sánchez NF, et al. Effect of crude plant extracts from some Oaxacan flora on two deleterious fungal phytopathogens and extract compatibility with a biofertilizer strain. Front Microbiol. 2014;5:383.

https://doi.org/10.3389/fmicb.2014.00383

6. Richardson DM, Pyšek P. Naturalization of introduced plants: Ecological drivers of biogeographical patterns. New Phytol. 2012;196:383-96.

https://doi.org/10.1111/j.1469-8137.2012.04292.x.

7. Weber E. The dynamics of plant invasions: a case study of three exotic goldenrod species (Solidago L.) in Europe. J Biogeogr. 1998;25:147-54.

https://doi.org/10.1046/j.1365-2699.1998.251119.x

8. Kołodziej B, Kowałski R, Kędzia B. Antibacterial and antimutagenic activity of extracts aboveground parts of three Solidago species: Solidago virgaurea L., Solidago canadensis L. and Solidago gigantea Ait. J Med Plants Res. 2011;5:6770-9. https://doi.org/10.5897/JMPR11.1098 
9. Kalemba D. Constituents of the essential oil of Solidago virgaurea L. Flavour Frag J. 1998;13:373-6.

https://doi.org/10.1002/(SICI)1099-

1026(199811/12)13:6<373::AID-FFJ749>3.0.CO;2-G

10. Kalemba D, Gora J, Kurowska A. Analysis of the essential oil of Solidago canadensis. Planta Med. 1990;56:222-3. https://doi.org/10.1055/s-2006-960930

11. Kalemba D, Marschall H, Bradesi P. Constituents of the essential oil of Solidago gigantea Ait. (giant goldenrod). Flavour Frag J. 2001;16:19-26.

https://doi.org/10.1002/1099-

1026(200101/02)16:1<19::AID-FFJ940>3.0.CO;2-U

12. Kalemba D, Thiem B. Constituents of the essential oils of four micropropagated Solidago species. Flavour Frag J. 2004;19:40-3.

https://doi.org/10.1002/ffj.1271

13. Anžlovar S, Dolenc Koce J. Antibacterial and antifungal activity of aqueous and organic extracts from indigenous and invasive species of goldenrod (Solidago spp.) grown in Slovenia. Phyton. 2014;54:135-47.

14. Deng Y, Zhao Y, Padilla-Zakour O, Yang G. Polyphenols, antioxidant and antimicrobial activities of leaf and bark extracts of Solidago canadensis L. Ind Crop Prod. 2015;74:803-9.

https://doi.org/10.1016/j.indcrop.2015.06.014

15. Starks CM, Williams RB, Goering MG, O'Neil-Johnson M, Norman VL, Hu JF, et al. Antibacterial clerodane diterpenes from goldenrod (Solidago virgaurea). Phytochemistry. 2010;71:104-9.

https://doi.org/10.1016/j.phytochem.2009.09.032

16. Thiem B, Goślińska O. Antimicrobial activity of Solidago virgaurea L. from in-vitro cultures. Fitoterapia. 2002;73:514-6. https://doi.org/10.1016/S0367-326X(02)00180-6

17. Mishra D, Joshi S, Bisht G, Pilkhwal S. Chemical composition and antimicrobial activity of Solidago canadensis Linn. root essential oil. J Basic Clin Pharm. 2010;1:187-90.

18. Mishra D, Joshi S, Pilkhwal S, Bisht G. Chemical composition, analgesic and antimicrobial activity of Solidago canadensis essential oil from India. J Pharm Res. 2011;4:63-6.

19. Morel AF, Dias GO, Porto C, Simionatto E, Stuker CZ, Dalcol II. Antimicrobial activity of extractives of Solidago microglossa. Fitoterapia. 2006;77:453-5.

https://doi.org/10.1016/j.fitote.2006.05.006

20. Chevalier M, Medioni E, Prêcheur I. Inhibition of Candida albicans yeast-hyphal transition and biofilm formation by Solidago virgaurea water extracts. J Med Microbiol. 2012;61:1016-22.

https://doi.org/10.1099/jmm.0.041699-0

21. Laurençon L, Sarrazin E, Chevalier M, Prêcheur I, Herbette G, Fernandez X. Triterpenoid saponins from the aerial parts of Solidago virgaurea alpestris with inhibiting activity of Candida albicans yeast-hyphal conversion. Phytochemistry. 2013;86:103-11.

https://doi.org/10.1016/j.phytochem.2012.10.004
22. Peng W, Qin R, Li X, Zhou H. Botany, phytochemistry, pharmacology, and potential application of Polygonum cuspidatum Sieb.et Zucc.: a review. J Ethnopharmacol. 2013;148:729-45.

https://doi.org/10.1016/j.jep.2013.05.007

23. Herpigny B, Dassonville N, Ghysels P, Mahy G, Meerts P. Variation of growth and functional traits of invasive knotweeds (Fallopia spp.) in Belgium. Plant Ecol. 2012;213:419-30. https://doi.org/10.1007/s11258-011-9989-9

24. Fan P, Hay AE, Marston A, Lou H, Hostettmann K. Chemical variability of the invasive neophytes Polygonum cuspidatum Sieb. and Zucc. and Polygonum sachalinensis F. Schmidt ex Maxim. Biochem Syst Ecol. 2009;37:24-34. https://doi.org/10.1016/j.bse.2008.11.018

25. Frantík T, Kovářová M, Koblihová H, Bartůňková K, Nyvltová Z, Vosátka M. Production of medically valuable stilbenes and emodin in knotweed. Ind Crop Prod. 2013;50:237-43. https://doi.org/10.1016/j.indcrop.2013.07.017

26. Chen H, Tuck T, Ji X, Zhou X, Kelly G, Cuerrier A, Zhang J. Quality assessment of Japanese knotweed (Fallopiajaponica) grown on Prince Edward Island as a source of resveratrol. J Agric Food Chem. 2013; 61:6383-92. https://doi.org/10.1021/jf4019239

27. Flavors and Fragrances Natural and Synthetic Compounds spectral library (FFNSC 3), Shimadzu Europa GmbH, Duisburg, Germany; 2015. Available from: https://www.shimadzu.eu/mass-spectral-libraries-and-databases.

28. NIST Special Database 14. National Institute of Standards and Technology, Gaithersburg, MD; USA; 2014. Available from: https://www.nist.gov/srd/nist-special-database-14.

29. Zabka M, Pavela R, Slezakova L. Antifungal effect of Pimenta dioica essential oil against dangerous pathogenic and toxinogenic fungi. Ind Crop Prod. 2009;30:250-3.

https://doi.org/10.1016/j.indcrop.2009.04.002

30. Anžlovar S, Baričevič D, Ambrožič Avguštin J, Dolenc Koce J. Essential oil of common thyme as a natural antimicrobial food additive. Food Technol Biotechnol. 2014;52:263-8.

31. GraphPad Prism v. 5.01 for Windows, GraphPad Software Inc., La Jolla, CA, USA; 2007. Available from: www.graphpad.com.

32. El-Sherei M, Khaleel A, Motaal AA, Abd-Elbaki P. Effect of seasonal variation on the composition of the essential oil of Solidago canadensis cultivated in Egypt. J Essent Oil Bear PI. 2014;17:891-8.

https://doi.org/10.1080/0972060X.2014.901612

33. Amtmann M. The chemical relationship between the scent features of goldenrod (Solidago canadensis L.) flower and its unifloral honey. J Food Compos Anal. 2010;23:122-9. https://doi.org/10.1016/j.jfca.2009.10.001

34. Weyerstahl P, Marschall H, Christiansen C, Kalemba D, Gora J. Constituents of the essential oil of Solidago canadensis (goldenrod) from Poland - a correction. Planta Med. 1993;59:281-2.

https://doi.org/10.1055/s-2006-959673 
35. Grul'ová D, Baranová B, Ivanova V, De Martino L, Mancini E, De Feo V. Composition and bioactivity of essential oils of Solidago spp. and their impact on radish and garden cress. Allelopathy J. 2016;39:129-42.

36. Webster D, Taschereau P, Belland R, Sand C, Rennie R. Antifungal activity of medicinal plant extracts; preliminary screening studies. J Ethnopharmacol. 2008;115:140-6. https://doi.org/10.1016/j.jep.2007.09.014

37. Bailey JP, Bímová K, Mandák B. Asexual spread versus sexual reproduction and evolution in Japanese knotweed s.l. sets the stage for the 'Battle of the clones'. Biol Invasions. 2009;11:1189-203.

https://doi.org/10.1007/s10530-008-9381-4

38. Flores FJ, Garzon CD. Detection and assessment of chemical hormesis on the radial growth in vitro of oomicetes and fungal plant pathogens. Dose-Response. 2012;11:361-73. https://doi.org/10.2203/dose-response.12-026.Garzon

39. Sultana B, Anwar F, Ashraf M. Effect of extraction solvent/ technique on the antioxidant activity of selected medicinal plant extracts. Molecules. 2009;14:2167-80.

https://doi.org/10.3390/molecules14062167

40. Hyldgaard M, Mygind T, Meyer RL. Essential oils in food preservation: mode of action, synergies, and interactions with food matrix components. Front Microbiol. 2012;3:12. https://doi.org/10.3389/fmicb.2012.00012

41. Elshafie HS, Grul'ová D, Baranová B, Caputo L, De Martino L, Sedlák V, et al. Antimicrobial activity and chemical composition of essential oil extracted from Solidago canadensis L. growing wild in Slovakia. Molecules. 2019;24:1206.

https://doi.org/10.3390/molecules24071206
42. Calo JR, Crandall PG, O'Brian CA, Ricke SC. Essential oils as antimicrobials in food systems. Food Control. 2015;54:111-9. https://doi.org/10.1016/j.foodcont.2014.12.040

43. Liu GY, Nizet V. Color me bad: microbial pigments as virulence factors. Trends Microbiol. 2009;17:406-13. https://doi.org/10.1016/j.tim.2009.06.006

44. Liu S, Shao X, Wei Y, Li Y, Xu F, Wang H. Solidago canadensis L. essential oil vapor effectively inhibits Botrytis cinerea growth and preserves postharvest quality of strawberry as a food model system. Front Microbiol. 2016;7:1179 https://doi.org/10.3389/fmicb.2016.01179

45. Butcko VM, Jensen RJ. Evidence of tissue-specific allelopathic activity in Euthamia graminifolia and Solidago canadensis (Asteraceae). Am Midl Nat. 2002:148:253-62. https://doi.org/10.1674/0003-0031(2002)148[0253:EOTSAA]2.0.CO;2

46. Dudai N, Mayer AM, Poljakoff-Mayber A, Putievsky E, Lerner HR. Essential oils as allelochemicals and their potential use as bioherbicides. J Chem Ecol. 1999;25:1079-89. https://doi.org/10.1023/A:1020881825669

47. Scrivanti LR, Zunino MP, Zygadlo JA. Tagetes minuta and Schinus areira essential oils as allelopathic agents. Biochem Syst Ecol. 2003;31:563-72. https://doi.org/10.1016/S0305-1978(02)00202-8

48. Verdeguer M, Amparo Blázquez M, Boira H. Phytotoxic effects of Lantana camara, Eucalyptus camaldulensis and Eriocephalus africanus essential oils in weeds of Mediterranean summer crops. Biochem Syst Ecol. 2009;37:362-69. https://doi.org/10.1016/j.bse.2009.06.003

49. Pršin T, Anžlovar S, Dolenc Koce J. The effect of thyme essential oil on germination and early growth of wheat. Acta Biol Slo. 2018;61:3-12. 